was not as desired, and in anticipation of the onset of adverse effects.

The most frequent switch was from morphine to methadone because it had a better pharmacodynamic profile on NMDA receptors.?

This study has a key weakness: the fact that pain is a multidimensional symptom with emotional, spiritual, and social factors that affect children's quality of life and symptom control.

\section{REFERENCES}

1. Goldman A, Hain R, Liben S. Symptom Care. In: Oxford Textbook of Palliative Care for Children. 2nd ed. New York: Oxford University Press; 2012:192-270.

2. Instituto Nacional del Cáncer. El dolor y el cáncer. Versión para profesionales de salud. [Accessed on: June 20 $0^{\text {th }}, 2017$ ]. Available at: https: / / www.cancer.gov/espanol/cancer/ tratamiento/efectos-secundarios/dolor/dolor-pro-pdq.

3. OMS. Directrices de la OMS sobre el tratamiento farmacológico del dolor persistente en niños con enfermedades médicas. 2012. [Accessed on: June 20 ${ }^{\text {th }}$, 2017]. Available at: http:/ / apps.who.int/medicinedocs / documents/s19116es/s19116es.pdf.

4. Astudillo W, Astigarraga I, Salinas A, et al. Manejo de síntomas. In: Medicina Paliativa en Niños y Adolescentes. San Sebastián: Paliativos sin Fronteras; 2015:285-306.

5. McGrath P, Stevens B, Walker S, et al. Pharmacological Interventions. Oxford Textbook of Paediatric Pain. New York: Oxford University Press; 2014.

6. Vara Hernando F, García Ortega E, Garzón Vázquez C, et al. El uso de la metadona en el tratamiento del dolor del enfermo terminal. V Congreso Sociedad Española del Dolor. [Accessed on: August 18 ${ }^{\text {th }}$, 2017]. Available at: http: / / revista.sedolor.es/pdf/2002_11_67.pdf.

7. González-BarboteoJ, Trelis-NavarroJ, Tuca-RodríguezA, et al. Rotación de opioides: una alternativa en el tratamiento del dolor refractario en pacientes con cáncer. Med Clin (Barc) 2010;135(13):617-22

8. Zernikow B, Michel E, Craig F, et al. Use of Opioids for the Management of Pain. Pediatr Drugs 2009;11(2):129-51.

9. Anghelescu D, Faughnan L, Hankins GM, et al. Methadone use in children and young adults at a cancer center: A retrospective study. J Opioid Manag 2011;7(5):353-61.

10. Davies D, DeVlaming D, Hainnes C. Methadone Analgesia for Children With Advanced Cancer. Pediatr Blood Cancer 2008;51(3):393-7.

11. Mercadante S, Ferrera P, Casuccio A, et al. Frequency, Indications, Outcomes, and Predictive Factors of Opioid Switching in an Acute Palliative Care Unit. J Pain Symptom Manage 2009;37(4):632-41.

\title{
Labial adhesions: Experience in a children's hospital
}

\author{
Anahí Rubinstein, M.D. ${ }^{a}$, Gisel Rahman, M.D. ${ }^{a}$, Paula Risso, B.S. ${ }^{b}$ and Dolores Ocampo, M.D. ${ }^{a}$
}

\begin{abstract}
Labial adhesions are defined as the complete or partial fusion of the pudendal cleft due to the agglutination of the labia minora in the midline. They most commonly occur between 3 months and 6 years of life.
\end{abstract}

a. Unit of Pediatric and Adolescent Gynecology, Hospital de Niños "Sor María Ludovica," La Plata, Province of Buenos Aires, Argentina.

b. Scientific Research Commission (Comisión de Investigaciones Científicas, CIC) of the Province of Buenos Aires, Chair of Classical and Bayesian Biostatistics, Degree of Clinical and Industrial Microbiology, School of Veterinary Sciences, Universidad Nacional de La Plata (UNLP), La Plata, Province of Buenos Aires, Argentina.

E-mail addres:

Anahí Rubinstein, M.D.: avrubinstein@yahoo.com.ar

Funding: None.

Conflict of interest: None.

Received: 3-11-2017

Accepted: 8-4-2017
Between January $1^{\text {st }}, 2002$ and December 31 ${ }^{\text {st }}, 2015,425$ girls diagnosed with labial adhesions and seen at the Unit of Pediatric and Adolescent Gynecology of Hospital de Niños de La Plata, Argentina, were analyzed. Their average age was 2.7 years (standard deviation: 2.6years). The most common presentation of labial adhesions was that involving more than $75 \%$ of the total length of the labia $(p<0.0000001)$. A total of $84.2 \%$ of patients showed no symptoms and $4 \%$ had urinary symptoms. Also, $68.4 \%$ of the girls who had a history of urinary tract infection had labial adhesions with a length of involvement of $>75 \%$. Finally, $90.6 \%$ of cases resolved with topical estrogens; and $2.1 \%$ had adverse events.

Key words: labial adhesions, girls, treatment.

http:/ / dx.doi.org/10.5546/ aap.2018.eng.65

To cite: Rubinstein A, Rahman G, Risso P, et al. Labial adhesions: Experience in a children's hospital. Arch Argent Pediatr 2018;116(1):6568.

\section{INTRODUCTION}

Labial adhesions during childhood, also referred to as labial agglutination, are defined as the complete or partial fusion of the pudendal 
cleft due to the agglutination of the labia minora in the midline. The etiology of this condition is related to low levels of estrogens, in association with vulvar inflammatory processes: inadequate hygiene, diaper use, vulvovaginitis, skin conditions, masturbation, and trauma. ${ }^{1}$

Diagnosis is made by inspecting the vulva with the Capraro maneuver. If fusion is complete, a sagittal line is visualized from the perineum to the clitoris and the structures of this area (urethral meatus, hymen, and vaginal opening) cannot be identified. In the case of partial labial agglutination, their length is variable. ${ }^{2}$

This is an acquired, benign condition that is not ordinarily observed in newborn infants due to the effects of maternal estrogens. In pediatrics, the prevalence of labial adhesions is $1.8 \% .^{3}$ They commonly occur between 3 months and 6 years of life. And they are usually asymptomatic. ${ }^{4}$ Blockage of the free flow of urine may predispose to post void dribbling, difficult urination, and urinary tract infection (UTI). The initial management consists in implementing hygiene conditions and applying estrogen cream. ${ }^{5}$

The objective of this article was to describe patients diagnosed with labial adhesions, describe their associated signs and symptoms, the relationship between UTI and the extent of labial adhesions, and assess the response to treatment and its adverse events.

\section{MATERIAL AND METHODS}

Patients with labial adhesions seen at the Unit of Pediatric and Adolescent Gynecology of Hospital de Niños de La Plata between January $1^{\text {st }}, 2002$ and December 31 ${ }^{\text {st }}, 2015$ were included. Patients referred with an inadequate diagnosis were excluded.

In the presence of an adult caregiver, the patients' case history was recorded and a physical examination was done. Labial agglutination was diagnosed if the labia minora were adhered in the midline and it was classified into three categories: less than $50 \%$, between $50 \%$ and $75 \%$, and greater than $75 \%$ in length. The presence of UTI, local inflammation, associated symptoms, and a history of traumatic debridement were recorded in the patients' medical records.

Each treatment course consisted in the application of estrogen cream twice daily for three weeks. Single treatment was defined as the complete or partial resolution of labial adhesions with only one course; treatment failure was defined as the lack of change after the first course; and multiple treatment was defined if more than one course was required for resolution. Thelarche and / or vulvar hyperpigmentation were considered adverse events of estrogen therapy.

\section{Statistical method}

This was a retrospective, longitudinal, descriptive and analytical study. Girls who received treatment and showed resolution of labial adhesions were compared to those without resolution, labial adhesions with a length of involvement of more than $75 \%$ were compared to the other types of labial adhesions, and the presence of UTI was assessed across the three categories defined here. In all cases, a Bayesian analysis of the difference of two proportions was used. ${ }^{6}$ The mean difference (MD) and the 95\% Bayesian credible interval (BCI) were estimated. The Epidat 4.1 software was used for statistical analysis. ${ }^{7}$ The level of significance was set at $p<0.05$.

\section{Ethical considerations}

This was an observational, retrospective study so it was not necessary to request an informed consent. Data were anonymized. The study was approved by the hospital's Teaching and Research Board.

\section{RESULTS}

A total of 425 girls were analyzed; their average age was 2.7 years (standard deviation: 2.6 years), age range: $0.1-14.8$ years (see Annex).

The most common presentation of labial adhesions was that involving more than $75 \%$ of the total length of the labia: $78.8 \%(n=335)$ $(p<0.0000001)$. Adhesions between $50 \%$ and $75 \%$ corresponded to $12 \%(n=51)$, and of less than $50 \%$, to $9.2 \%(\mathrm{n}=39)$.

In the initial visit, $84.2 \%(\mathrm{n}=358)$ of patients had no symptoms, $4 \%(\mathrm{n}=17)$ had difficult urination, $8.9 \%(n=38)$ had a confirmed UTI, and $2.8 \%$ $(n=12)$ referred a history of alleged sexual abuse.

Among the girls who had a history of UTI, $68.4 \%$ had labial adhesions with a length of involvement of $>75 \%$, which was the most common presentation $(p<0.0001)$. In addition, statistically significant differences were observed between labial adhesions with $50-75 \%$ and $<50 \%$ of involvement ( $p=0.032$; Table 1).

The physical examination showed that $20.7 \%(n=88)$ of girls had vulvar erythema and $1.4 \%(n=6)$ had smegma accumulations in the 
interlabial folds.

Topical treatment was applied to $92.9 \%$ (395/425) of patients; $90.6 \%$ (358/395) of cases resolved: $60.6 \%(n=217)$ with the first treatment course; $28.2 \%(\mathrm{n}=101)$, with the second; and $11.2 \%$ $(\mathrm{n}=40)$, with the third. Treatment failure with the first course was recorded in $11.9 \%(n=47)$ of patients.

In $44.7 \%$ of cases $(21 / 47)$, it corresponded to errors in cream application, which resolved in $47.6 \%$ of patients $(10 / 21)$ with the second course.

Five patients had a history of traumatic debridement, either manual $(n=4)$ or surgical $(n=1)$, which resolved with topical management.

The proportion of girls with resolution was significantly higher than that without resolution: $358 / 395$ versus $37 / 395$ (MD: $0.808 ; 95 \%$ BCI: $0.766-0.848 ; p<0.00000001)$.

Treatment-associated adverse events were observed in 2.1\%: 6 corresponded to thelarche and 3 , to vulvar hyperpigmentation.

\section{DISCUSSION}

Labial adhesions are a common reason for consultation at the pediatric gynecology office. $^{2}$ At the Unit of Pediatric and Adolescent Gynecology of Hospital de Niños de La Plata, labial adhesions account for $6.1 \%$ of annual visits; and this percentage may be even higher because many girls have no symptoms.

In our study, $73.9 \%$ of cases were observed between 6 months and 3 years of age, similar to what has been described by Leung et al. ${ }^{3}$

Estrogen and local estrogen receptor levels at the vulva affect local healing processes. During tissue recovery, low estrogen levels may facilitate labial fusion.., 9

Although most patients have no symptoms, they may have difficult urination or a UTI, and sometimes vulvar erythema is observed. Among assessed girls, $20.7 \%$ had vulvar congestion, that may have been related to poor hygiene conditions and diaper use, which may promote local irritation.
Labial adhesions are a risk factor for UTIs, which occur in $3-5 \%$ of girls in the general population, but go up to $40 \%$ among those with labial adhesions. ${ }^{10}$

In the studied population, UTIs were observed in $8.9 \%$, and they were more common among those with complete labial adhesions, which was consistent with what has been reported by Melek et al. ${ }^{10}$

Asymptomatic patients with a smaller extent of agglutination only require observation. ${ }^{11}$ In our study, labial adhesions that involved less than $50 \%$ of the length and without urinary symptoms did not receive medical treatment and no subsequent visits were recorded.

Although other studies have established an association between labial adhesions and child sexual abuse, there is no consensus on the causality of labial adhesions and a history of child sexual abuse. ${ }^{12}$

Initial management with topical estrogens is considered safe, even with prolonged treatment courses. According to the bibliography, successful outcomes were reported in $50-80 \%$ of the treated population. ${ }^{8,13}$ Labial adhesions have been described to resolve between 2 and 8 weeks. ${ }^{9}$ In our study, $90.6 \%$ of cases resolved completely after treatment; $60.6 \%$ of them with the first treatment course.

Adverse events are transient, resolve once treatment is discontinued and are not related to the number of therapy courses indicated. ${ }^{1}$ Thelarche and vulvar hyperpigmentation were observed in $2.1 \%$ of assessed patients.

The response to topical treatment among girls with a history of manual and/or surgical debridement was successful, similar to what has been described by Capraro and Greenberg. ${ }^{14}$ Prescribing a topical treatment would be the first choice, even in cases of traumatic dehiscence.

In relation to the cream application method, it was observed that $47.6 \%$ of patients who did

TABLE 1. Comparison of girls with urinary tract infection based on the length of involvement of labial adhesions $(<50 \%$, $50-75 \%$, and $>75 \%$ )

\begin{tabular}{lccc}
\hline Comparison & Proportions & MD & 95\% BCI \\
\hline LA $>75 \%$ versus $50-75 \%$ & $26 / 38$ versus 9/38 & 0.426 & $0.225-0.612$ \\
LA $>75 \%$ versus $<50 \%$ & $26 / 38$ versus 3/38 & 0.575 & $0.396-0.734$ \\
LA $>75 \%$ versus $<50 \%$ & $9 / 38$ versus 3/38 & 0.150 & $-0.010-0.315$ \\
\hline
\end{tabular}

MD: mean differences; BCI: Bayesian credible interval; LA: labial adhesions.

A $p$ value of $<0.05$ was considered a statistically significant difference. 
not show changes with the initial treatment showed an effective response once the application technique was improved. Studies have demonstrated that an adequate technique with soft local pressure is critical for a successful resolution. ${ }^{15}$

Surgical resolution of labial adhesions should be reserved for topical refractory patients with severe blockage of the free flow of urine. Laufer and Emans have referred a history of surgical resolution in only one patient over 10 years. ${ }^{11} \mathrm{In}$ our experience, no patient required surgery.

The natural history of labial adhesions is that of spontaneous resolution with the development of the first signs of puberty.

The strengths of this study are the number of assessed patients and their subsequent followup, which helped to make conclusions in relation to topical treatment. However, since only a single topical treatment was indicated, it was not possible to compare it with other therapeutic options in pediatrics.

\section{CONCLUSION}

Labial adhesions are a common reason for consultation in Pediatric and Adolescent Gynecology. They are usually asymptomatic. The most common presentation was that involving more than $75 \%$ of the total length of the labia and which predisposes to UTIs. A high percentage of labial adhesions resolve with topical estrogens, which causes few adverse events.

\section{REFERENCES}

1. Granada C, Sokkary N, Sangi-Haghpeykar H, et al. Labial Adhesions and Outcomes of Office Management. J Pediatr Adolesc Gynecology 2015;28(2):109-13.
2. Pereyra Pacheco B. Coalescencia de labios menores. In: Sanchez de la Cruz B. Ginecología Infantojuvenil. Buenos Aires: Panamericana; 2011. Pages 91-8.

3. Leung AKC, Robson WL, Tay-Uyboco J. The incidence of labial fusion in children. J Paediatr Child Health 1993; 29(3):235-6.

4. Bacon J, Romano M, Quint E. Clinical Recommendation: Labial Adhesions. JPediatr Adolesc Gynecol 2015;28(5):405-9.

5. Trebuegge M, Misra I, Nerminathan V. Is the topical application of oestrogen cream an effective intervention in girls suffering from labial adhesions? Arch Dis Child 2007;92(3):268-71.

6. Risso MA, Risso P. Introducción a la Estadística Bayesiana: Uso de Lenguaje R y WinBUGS. La Plata: Vuelta a Casa; 2017.

7. Epidat: Programa para Análisis Epidemiológico de Datos. Versión 4.1, octubre 2014. Consellería de Sanidad, Xunta de Galicia, España; Organización Panamericana de la Salud (OPS-OMS); Universidad CES, Colombia. [Accessed on: May 19 ${ }^{\text {th }}, 2016$ ]. Available at: http://www.sergas.es/ Saude-publica/EPIDAT?idioma $=$ es.

8. Seyer T. Topical estrogen therapy in labial adhesions in children: therapeutic or prophylactic? J Pediatr Adolesc Gynecol 2007;20(4):241-4.

9. Mayoglou L, Dulabon L, Martin-Alguacil N, et al. Success of treatment modalities for labial fusion: a retrospective evaluation of topical and surgical treatments. J Pediatr Adolesc Gynecol 2009;22(4):247-50.

10. Melek E, Kılıçbay F, Sarıkaş NG, et al. Labial adhesion and urinary tract problems: the importance of genital examination. J Pediatr Urol 2016;12(2):111.e1-5.

11. Laufer MR, EmansSJ. Vulvovaginal complaints in the prepubertal child. UpToDate [Accesed on: January ${ }^{\text {th }}$, 2016]. Available at: http: / / cursoenarm.net/UPTODATE / contents / mobipreview.htm?7/31/7664.

12. Kumar RK, Sonika A, Charu C, et al. Labial adhesions in pubertal girls. Arch Gynecol Obstet 2006;273(4):243-5.

13. Eroğlu E, Yip M, Oktar T, et al. How should we treat prepubertal labial adhesions? Retrospective comparison of topical treatments: estrogen only, bethametasone only, and combination estrogen and bethametasone. J Pediatr Adolesc Gynecol 2011;24(6):389-91.

14. Capraro VJ, Greenberg H. Adhesions of labia minora. Obstet Gynecol 1972:39(1):65-9.

15. Kumetz LM, Quint EH, Fisseha S, et al. Estrogen treatment success in recurrent and persistent labial agglutination. J Pediatr Adolesc Gynecol 2006;19(6):381-4. 
ANNEX

Distribution of cases by girls' age

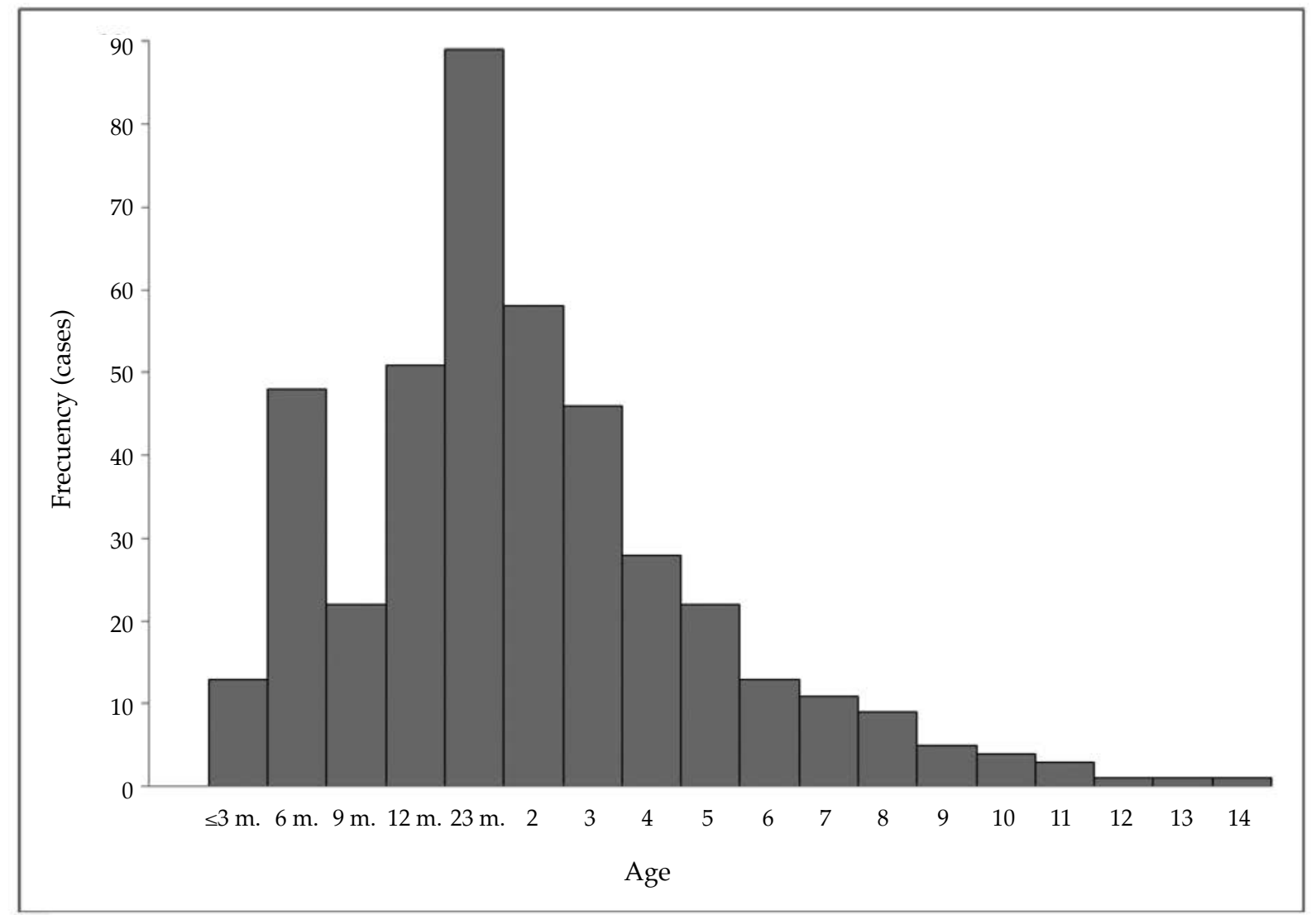

m: months old. Age is expressed in years old (decimal age), except for the first 23 months of life. 